\title{
Childhood blood pressure, body build, and birthweight: geographical associations with cardiovascular mortality
}

\author{
P H Whincup, D G Cook, O Papacosta, M Walker
}

\begin{abstract}
Study objective-The aim was to examine whether blood pressure, body build, and birthweight differ between areas of England and Wales with widely differing adult cardiovascular mortality rates.

Design-This was a cross sectional survey of children in five towns with exceptionally high and five towns with exceptionally low current adult cardiovascular mortality.

Setting-The study was a school based survey.

Subjects -3842 children aged $5 \cdot 0-7 \cdot 5$ years were selected by stratified random sampling of primary schools (response rate 76\%).

Measurements and main results-Blood pressure, pulse rate, height, and weight were measured and birthweight was assessed by maternal recall. Children in towns with high cardiovascular mortality rates were significantly shorter than those in towns with low cardiovascular mortality rates (mean difference $0.9 \mathrm{~cm}, 95 \%$ confidence interval 0.4 to $1.4 \mathrm{~cm}$ ) and had slightly higher body mass indices (mean difference $0.12 \mathrm{~kg} / \mathrm{m}^{2}, 95 \%$ CI -0.03 to $0.27 \mathrm{~kg} / \mathrm{m}^{2}$ ). Mean birthweights were slightly lower in high mortality towns (mean difference $34 \mathrm{~g}$, $95 \% \mathrm{CI}-10$ to $78 \mathrm{~g}$ ), while the proportion of children with low birthweight $(<2500 \mathrm{~g})$ $(8 \cdot 1 \%)$ was significantly higher than that in low mortality towns $(5.5 \%)(p=0.005)$. Mean differences in blood pressure between high and low mortality towns were small and non-significant, even after adjustment for height. The differences in height between high and low mortality towns were largely independent of social class. However, differences in mean birthweight were markedly reduced once social class was taken into account.
\end{abstract}

Conclusions-No geographical relationship between childhood blood pressure and adult cardiovascular mortality was detected. Although it is possible that the differences in mean height and body mass index between towns with differing adult cardiovascular mortality may have implications for future patterns of health in these towns, the absence of marked differences in birthweight and blood pressure suggests that hypotheses proposing a direct relationship between intrauterine experience and adult cardiovascular mortality will have limited relevance to geographical variation in cardiovascular disease in this generation.

f Epidemiol Community Health 1992; 46: 396-402
Understanding the reasons for variation in the average blood pressure levels of different population groups is an important aspect of the study of high blood pressure. ${ }^{1}$ Marked differences in the average blood pressure levels of middle aged men (40-59 years) in different British towns have been observed, which are related to geographical variation in cardiovascular mortality rates. ${ }^{2}$ These findings have been confirmed and extended to middle aged women and to younger subjects aged 25-29 years. ${ }^{3}$ Differences in the average blood pressure levels of 5-7 year old children have also been observed, which appeared to be related both to town mean blood pressure levels in adults and to adult cardiovascular mortality rates. ${ }^{4}$ The results of the latter study suggested that the geographical differences in adult blood pressure within Britain might have their origins, at least in part, in the first years of life. However, the conclusions were strongly influenced by the exceptionally low blood pressure observed in one town (Guildford) and clearly required substantiation.

A new study of childhood blood pressure levels has been conducted in 10 different towns in England and Wales; five with exceptionally high and five with exceptionally low rates of adult cardiovascular mortality. The principal aim of the study was to examine the earlier observation of a relationship between childhood blood pressure level and adult cardiovascular mortality. ${ }^{4}$ However, the study also provided an opportunity to examine whether there are differences in birthweight, height, and other measures of body size in children born in the 1980 s in towns with widely differing adult cardiovascular mortality rates. These observations are likely to be of particular interest in the context of reports suggesting a direct connection between early life experience and later cardiovascular mortality. These include, first, reports relating adult height to mortality from ischaemic heart disease, ${ }^{56}$ and second, reports suggesting that experiences in fetal and infant life might be directly related to the development of hypertension ${ }^{78}$ and cardiovascular disease, ${ }^{910}$ and might play an important role in the explanation of geographical variations in cardiovascular disease within Britain. ${ }^{711} 12$ Trends in ischaemic heart disease to the year 2000 have recently been examined in the light of these hypotheses. ${ }^{13}$ The extent of differences in height and birthweight in children from geographical areas with widely different current adult cardiovascular mortality rates may provide an indication of the potential importance of these hypotheses for cardiovascular disease in the next generation. 


\section{Methods}

SAMPLING PROCEDURES

The $\mathbf{4 0 6}$ local authority districts in England and Wales were ranked on the basis of their standardised mortality ratios for all cardiovascular disease for 1979-1983, calculated for men and women aged 35-64 years. The five highest and five lowest mortality districts containing a population centre of 40000-100000 subjects (similar in size to those in the earlier study) were selected. However, those districts including the towns in the earlier study ${ }^{4}$ were excluded. One low mortality town (Cambridge) was withdrawn because of extensive existing school research commitments and replaced by the town with the sixth lowest mortality (Tunbridge Wells). The geographical distribution of the study towns is shown in the figure. The decision to include 10 towns was based on assessment of the relationship between childhood blood pressure and adult cardiovascular mortality rate in the earlier study, ${ }^{4}$ which suggested that a difference of more than $3 \mathrm{~mm} \mathrm{Hg}$ in systolic pressure would have been expected between towns with exceptionally high and exceptionally low cardiovascular mortality. For an analysis of differences in systolic pressure between the five high and five low mortality towns, the study design had more than $80 \%$ power for detection of a systolic difference of $3 \mathrm{~mm} \mathrm{Hg}$ and more than $90 \%$ power for detection of a difference of $4 \mathrm{~mm}$ $\mathrm{Hg}$ at a two sided $\mathrm{p}$ value of 0.05 , given the observed standard deviation of $1.5 \mathrm{~mm} \mathrm{Hg}$ for average systolic pressure within the high and low mortality town groups.

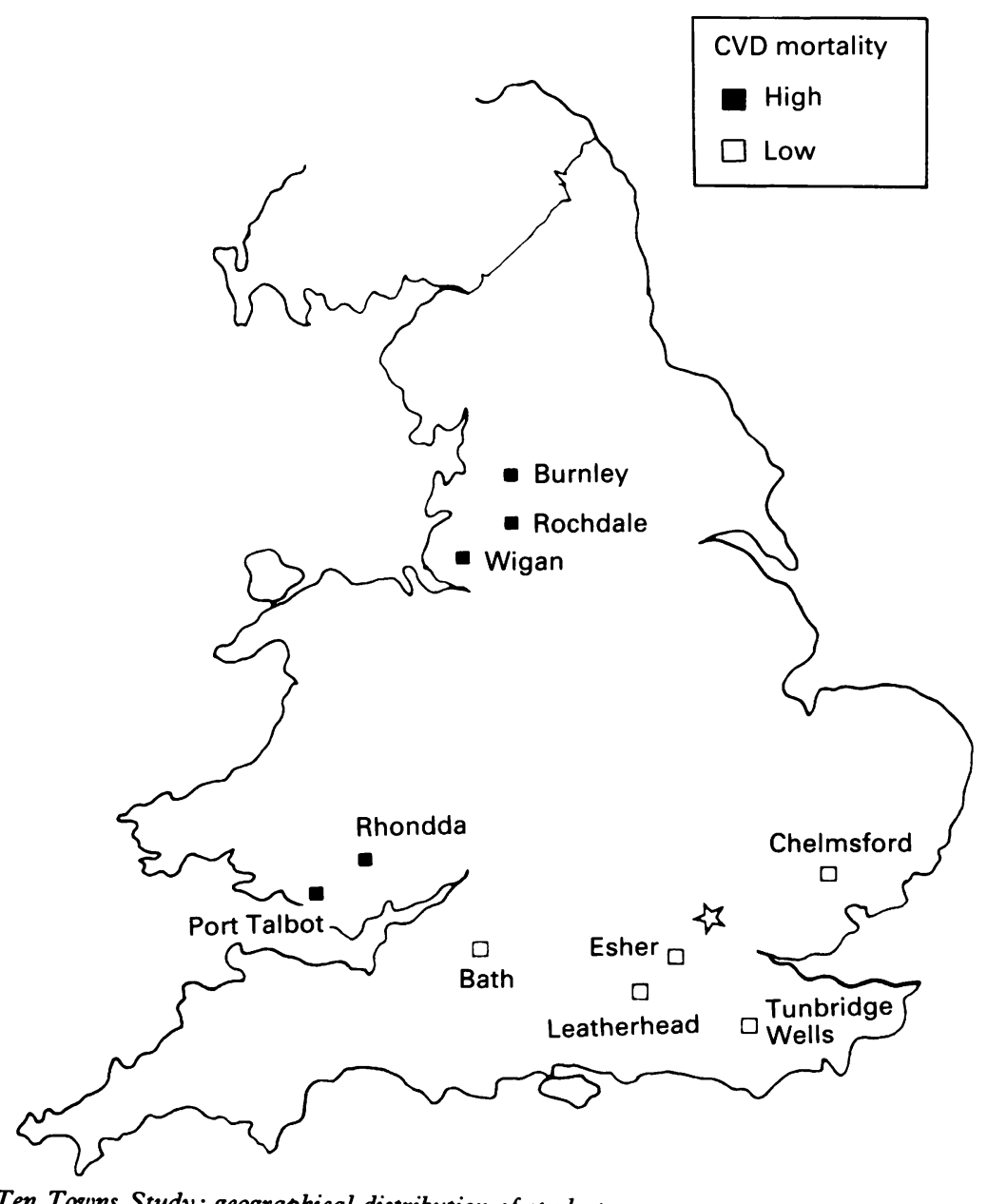

Within each town, the approval of the local ethics committee and the education authority was sought and a list of all primary schools in the town obtained. A random sample of 10 schools, stratified by denomination and, in the case of county primary schools, by size and location, was selected in each town. Of the 100 invited schools, 15 were unable to take part (five in high mortality towns and 10 in low mortality towns) and were replaced by the school matching most closely in denomination, size, and location. In each school two classes containing children aged between 5.0 and 7.5 years were randomly selected to provide 50 to 60 children who were invited to participate. This method is the same as that used in the earlier study, ${ }^{4}$ validated using data from the 1981 census $10 \%$ sample. All subjects received a letter of invitation from the head teacher and a reminder if they did not reply to the initial invitation.

\section{SURVEY PROCEDURES}

All measurements were made between January and July 1990 by a team of four trained nurse observers working in pairs. Towns in low and high mortality areas were examined alternately; towns in close geographical proximity were not examined consecutively. All schools in each town were examined in a five day period; individual schools were visited for one day. Each observer made approximately one quarter of all measurements in each town. Working procedures were standardised for all schools and measurements were performed in the medical room or similar accommodation. Measurements were carried out with the children dressed in light clothing without shoes, after resting for a period of at least five minutes. Height was measured to the last complete millimetre using either a Holtain electronic stadiometer or a CMS portable stadiometer. Weight was measured to the last complete $0 \cdot 1 \mathrm{~kg}$ with a Soehnle digital electronic weighing scale. Right arm circumference was measured to the last complete millimetre at the midpoint between the acromial process and the olecranon with the arm pendant. Blood pressure was measured in the right arm with the child seated and the arm supported at chest level, using the Dinamap 1846SX automated oscillometric blood pressure recorder (Critikon, Inc) ${ }^{1415}$ to record two blood pressure measurements with a one minute interval in the right arm. All measurements were made with the child cuff size (bladder dimensions $15.5 \times 8 \mathrm{~cm}$ ), ensuring that the cuff width/arm circumference ratio of $40-50 \%$ recommended by the American Heart Association ${ }^{16}$ was met for $79 \%$ of the study population. Ethnic group was assessed on the basis of the child's appearance. Room temperature was measured to the nearest $0 \cdot 1^{\circ} \mathrm{C}$ with an RS digital thermometer and thermocouple at the time of each set of blood pressure measurements. Data on external temperature, recorded hourly at local meteorological stations, was provided by the Meteorological Office. A self administered questionnaire sent to the parents of all participants on the day of examination was used to provide information on birth weight, parental height and weight, and social class. Mothers were asked to record the child's birth weight as accurately as possible; the validity of maternal recall after a five to seven year period had previously been demon- 
strated. ${ }^{17}$ Social class was determined for both parents on the basis of present or most recent occupation, classified according to the Registrar General's six social classes with the 1980 manual of the Office of Population, Censuses and Surveys (OPCS). Analyses in this paper refer to the head of household (male in 93\%) as defined by OPCS. ${ }^{18}$

\section{Standardisation of measurements}

The two blood pressure recorders were calibrated daily against a reference mercury column. A comparison of blood pressure measurement between the two blood pressure recorders at the beginning and end of the study revealed no evidence of significant measurement drift between instruments. A comparison of the two stadiometers revealed a systematic measurement difference of $1 \mathrm{~mm}$ between instruments; all measurements were standardised to the Holtain instrument for the analyses presented.

\section{STATISTICAL METHODS}

The analyses presented are based on town means or, where appropriate, percentages, for each variable. However, data are also presented on the proportion of overweight subjects and the proportion of subjects of low birthweight. Age and sex standardised town mean blood pressures have been derived from analyses of covariance in which blood pressure was regressed on age (fitted as a continuous variable), town (fitted as a factor with 10 levels), and sex (two levels). The same method has been used to provide standardised estimates of town means for the other variables. Where described, social class (fitted as a factor with six levels) has also been included in analyses. In order to examine whether variables differed systematically between high and low mortality towns, the adjusted high and low mortality town means have been compared using the unpaired $t$ statistic. The results of such analyses, based on

Table I Sex differences in age, blood pressure (BP), pulse rate, height, weight, body mass index, and birthweight

\begin{tabular}{|c|c|c|c|c|c|}
\hline & \multicolumn{2}{|c|}{ Boys $(n=1966)$} & \multicolumn{2}{|c|}{ Girls $(n=1876)$} & \multirow{2}{*}{$\begin{array}{l}p(\text { no sex } \\
\text { difference) }\end{array}$} \\
\hline & Mean & $S D$ & Mean & $S D$ & \\
\hline $\begin{array}{l}\text { Age (years) } \\
\text { Systolic BP (mm Hg) } \\
\text { Diastolic BP (mm Hg) } \\
\text { Pulse (beats } / \mathrm{min}) \\
\text { Height }(\mathrm{cm}) \\
\text { Weight }(\mathrm{kg}) \\
\text { Body mass index }\left(\mathrm{kg} / \mathrm{m}^{2}\right) \\
\text { Birthweight }(\mathrm{kg})\end{array}$ & $\begin{array}{c}6 \cdot 37 \\
103 \cdot 4 \\
61 \cdot 0 \\
88 \cdot 7 \\
117 \cdot 8 \\
21 \cdot 9 \\
15 \cdot 70 \\
3 \cdot 38\end{array}$ & $\begin{array}{c}0.63 \\
10.8 \\
7.5 \\
11.3 \\
6.0 \\
3.4 \\
1.48 \\
0.54\end{array}$ & $\begin{array}{c}6 \cdot 37 \\
104 \cdot 0 \\
61 \cdot 4 \\
90 \cdot 5 \\
117 \cdot 0 \\
21 \cdot 8 \\
15 \cdot 80 \\
3 \cdot 25\end{array}$ & $\begin{array}{c}0.63 \\
11.0 \\
7.3 \\
11.3 \\
6.4 \\
3.8 \\
1.72 \\
0.53 \\
\end{array}$ & $\begin{array}{l}0.98 \\
0.10 \\
0 \cdot 10 \\
<0.0001 \\
<0.0001 \\
0.24 \\
0.05 \\
<0.0001 \\
\end{array}$ \\
\hline
\end{tabular}

between town variance, have the advantage of allowing the findings to be generalised to all similar towns in England and Wales. Where appropriate, analyses of covariance have been used to examine whether variation between towns (irrespective of high/low mortality status) is likely to be due to chance. These analyses, which are based on both the individual and school day components of within town variance, cannot be generalised beyond the towns studied.

Weight $/$ height $^{2}$ is the weight for height index used in the analyses presented here. Overweight has been arbitrarily defined as being above the 95th centile of weight/height ${ }^{2}$ in the appropriate six month age-sex group. The distribution of birthweights was markedly skewed to the left. Since variation in the proportion of low birthweight $(<2500 \mathrm{~g})$ is of potential clinical significance, these proportions have been presented in addition to mean birthweights. Standardisation of the proportions of low birthweight for the effect of social class have been performed using logistic regression with the marginal prediction method. ${ }^{19}$

\section{Results}

Because earlier studies have indicated that patterns of cardiovascular risk factors differ between ethnic groups in Britain, ${ }^{20}$ the results presented are restricted to 3842 European children aged between 5.0 and 7.5 years. The overall response rate was $76 \%$; similar rates were observed both in high mortality towns $(75 \%)$ and in low mortality towns $(76 \%)$. Data on birthweight is based on 3286 subjects ( $86 \%$ of those examined) for whom study questionnaires were returned. In table I the means and standard deviations of the principal variables examined are presented for boys and girls separately. Mean systolic and diastolic pressure, pulse rate, and body mass index were slightly higher in girls, but only the differences in pulse rate and body mass index are statistically significant. Mean height, weight and birthweight were higher in boys; the differences in height and birthweight are statistically significant. Sex differences in all variables are taken into account in subsequent analyses, but have no important effect on the results.

Mean blood pressures and pulse rates for individual towns and for high and low mortality town groups are presented in table II. Although both the mean systolic and diastolic pressures were higher in the high mortality town group than
Table II Mean (SEM) systolic and diastolic blood pressure, pulse rate, pressure, pulse rate,
height, weight, and body mass index by town in relation to adult cardiovascular standardised mortality ratio (SMR)

\begin{tabular}{|c|c|c|c|c|c|c|c|c|}
\hline \multirow[b]{2}{*}{ Town } & \multirow[b]{2}{*}{$S M R$} & \multirow[b]{2}{*}{$n$} & \multicolumn{2}{|c|}{ Blood pressure ( $\mathrm{mm} \mathrm{Hg}$ ) } & \multirow{2}{*}{$\begin{array}{l}\text { Pulse } \\
\text { (beats/min) }\end{array}$} & \multirow[b]{2}{*}{ Height $(\mathrm{cm})$} & \multirow[b]{2}{*}{ Weight (kg) } & \multirow{2}{*}{$\begin{array}{l}\text { Body mass } \\
\text { index }\left(\mathrm{kg} / \mathrm{m}^{2}\right)\end{array}$} \\
\hline & & & Systolic & Diastolic & & & & \\
\hline $\begin{array}{l}\text { Esher } \\
\text { Chelmsford } \\
\text { Leatherhead } \\
\text { Bath } \\
\text { Tunbridge Wells }\end{array}$ & $\begin{array}{l}64 \\
71 \\
70 \\
75 \\
71\end{array}$ & $\begin{array}{l}361 \\
444 \\
354 \\
382 \\
410\end{array}$ & $\begin{array}{l}101 \cdot 7(0.6) \\
105 \cdot 0(0 \cdot 5) \\
102 \cdot 9(0 \cdot 6) \\
102 \cdot 1(0.5) \\
104 \cdot 5(0.5)\end{array}$ & $\begin{array}{l}61 \cdot 0(0 \cdot 4) \\
62 \cdot 1(0 \cdot 3) \\
60 \cdot 3(0 \cdot 4) \\
59 \cdot 2(0 \cdot 4) \\
61 \cdot 9(0 \cdot 4)\end{array}$ & $\begin{array}{c}\text { Low mortality } \\
89.7(0.6 \\
90 \cdot 8(0.5) \\
88.5(0.6) \\
88 \cdot 1(0.6) \\
88 \cdot 8(0.5)\end{array}$ & $\begin{array}{l}117 \cdot 8(0 \cdot 2) \\
117 \cdot 6(0 \cdot 2) \\
118 \cdot 1(0 \cdot 3) \\
118 \cdot 2(0 \cdot 2) \\
117 \cdot 7(0 \cdot 2)\end{array}$ & $\begin{array}{l}21 \cdot 8(0 \cdot 2) \\
21 \cdot 8(0 \cdot 2) \\
22 \cdot 0(0 \cdot 2) \\
22 \cdot 0(0 \cdot 2) \\
21.9(0 \cdot 2)\end{array}$ & $\begin{array}{l}15.61(0.08) \\
15.69(0.07) \\
15.66(0.08) \\
15.70(0.08) \\
15.70(0.08)\end{array}$ \\
\hline Low mortality town group & - & 5 & $103 \cdot 3(0 \cdot 7)^{\star}$ & $60.9(0.6)^{\star}$ & $89.2(0.8)^{\star}$ & $117 \cdot 9(0 \cdot 1)^{\star}$ & $21 \cdot 9(0 \cdot 1)^{\star}$ & $15.67(0.05)^{\star}$ \\
\hline $\begin{array}{l}\text { Wigan } \\
\text { Port Talbot } \\
\text { Burnley } \\
\text { Rhondda } \\
\text { Rochdale }\end{array}$ & $\begin{array}{l}140 \\
143 \\
131 \\
138 \\
136\end{array}$ & $\begin{array}{l}460 \\
380 \\
411 \\
360 \\
280\end{array}$ & $\begin{array}{l}106 \cdot 0(0 \cdot 5) \\
104 \cdot 0(0 \cdot 5) \\
102 \cdot 2(0 \cdot 5) \\
104 \cdot 7(0 \cdot 6) \\
102 \cdot 5(0 \cdot 6)\end{array}$ & $\begin{array}{l}63 \cdot 5(0.3) \\
61 \cdot 2(0.4) \\
59 \cdot 4(0.4) \\
61 \cdot 3(0 \cdot 4) \\
61 \cdot 0(0.4)\end{array}$ & $\begin{array}{c}\text { High mortality } \\
92 \cdot 4(0.5) \\
91 \cdot 8(0.6) \\
89.6(0.5) \\
87.6(0.6) \\
87 \cdot 2(0.7)\end{array}$ & $\begin{array}{l}116.7(0.2 \\
117.6(0.2) \\
116.8(0.2) \\
116.5(0.3) \\
117.0(0.3)\end{array}$ & $\begin{array}{l}21 \cdot 5(0 \cdot 1) \\
22 \cdot 2(0 \cdot 2) \\
21 \cdot 6(0 \cdot 2) \\
21 \cdot 7(0 \cdot 2) \\
21 \cdot 6(0 \cdot 2)\end{array}$ & $\begin{array}{l}15.70(0.07) \\
15.98(0.08) \\
15.78(0.08) \\
15.93(0.08) \\
15.64(0.09)\end{array}$ \\
\hline High mortality town group & - & 5 & $103.9(0.7)^{\star}$ & $61.3(0.6)^{\star}$ & $89.7(0.8)^{\star}$ & $117 \cdot 0(0 \cdot 1)^{\star}$ & $21 \cdot 7(0 \cdot 1)^{\star}$ & $15 \cdot 81(0.05)^{\star}$ \\
\hline p (high-low difference) & & & 0.54 & 0.66 & 0.66 & 0.002 & $0 \cdot 24$ & $0 \cdot 10$ \\
\hline
\end{tabular}

All values are adjusted for age and sex

$\star$ Based on between town differences 
in the low mortality town group the differences are small and not statistically significant (mean systolic difference $0.6 \mathrm{~mm} \mathrm{Hg}, 95 \%$ confidence interval (CI) -1.6 to $2.8 \mathrm{~mm} \mathrm{Hg}, \mathrm{p}=0.54$; mean diastolic difference $0.4 \mathrm{~mm} \mathrm{Hg}, 95 \% \mathrm{CI}-1.6$ to $2.4 \mathrm{~mm} \mathrm{Hg}, \mathrm{p}=0.66)$. However, the marked variation in mean blood pressures between the individual towns (range $4.3 \mathrm{~mm} \mathrm{Hg}$ systolic and diastolic) is statistically significant both for systolic $(p=0.03)$ and for diastolic pressure $(p=0.006)$. Pulse rates were marginally higher in the high mortality town group than in the low mortality town group, although the differences do not approach conventional levels of statistical significance (mean difference 0.5 beats $/ \mathrm{min}, 95 \%$ CI -2.2 to 3.2 beats $/ \mathrm{min}, \mathrm{p}=0.66$ ). However, variation in pulse rate between the study towns (range 5.2 beats $/ \mathrm{min}$ ) is highly significant $(p=0.001)$.

Mean heights, weights, and body mass indices in the different towns are also presented in table II. Children in the low mortality town group were significantly taller than those in the high mortality town group (mean height difference $0.9 \mathrm{~cm}, 95 \%$ CI 0.4 to $1.4, p=0.002$ ) and they were also slightly, though not significantly, heavier (mean difference $0.2 \mathrm{~kg}, 95 \% \mathrm{CI}-0.1$ to $0.5, \mathrm{p}=0.24$ ). Body mass indices were on average higher in towns with high mortality, although the differences do not achieve conventional levels of statistical significance (mean difference $0.12 \mathrm{~kg} / \mathrm{m}^{2}$, $95 \%$ CI -0.03 to $0 \cdot 27, p=0 \cdot 10$ ). Similarly, the proportion of overweight children (defined as the proportion above the 95th centile for the study population as a whole, standardised for sex and six month age group) was slightly higher in the high mortality towns $(5.7 \%)$ than in low mortality towns $(4 \cdot 1 \%)$; again the difference is of marginal statistical significance $(p=0.07)$. Town mean birthweights (table III) were lower on average in

Table III Mean birthweight and proportion of low birthweight $(<2500 \mathrm{~g})$ in towns with exceptionally high and exceptionally low adult cardiovascular mortality rates

Table IV Height, body mass index and birthweight by social class

\begin{tabular}{|c|c|c|c|}
\hline \multirow[b]{2}{*}{ Town } & \multirow[b]{2}{*}{$n$} & \multicolumn{2}{|c|}{ Birthweight $(\mathrm{g})$} \\
\hline & & Mean (SEM) & \\
\hline $\begin{array}{l}\text { Esher } \\
\text { Chelmsford } \\
\text { Leatherhead } \\
\text { Bath } \\
\text { Tunbridge Wells }\end{array}$ & $\begin{array}{l}333 \\
410 \\
296 \\
343 \\
354\end{array}$ & $\begin{array}{l}\text { Low mortality } \\
3296(30) \\
3328(27) \\
3343(31) \\
3339(29) \\
3333(29)\end{array}$ & $\begin{array}{l}y \\
6 \cdot 3 \\
5 \cdot 1 \\
5 \cdot 1 \\
5 \cdot 0 \\
5 \cdot 9\end{array}$ \\
\hline $\begin{array}{l}\text { Low mortality } \\
\text { town group }\end{array}$ & 5 & $3328(14)^{\star}$ & $5 \cdot 5$ \\
\hline $\begin{array}{l}\text { Wigan } \\
\text { Port Talbot } \\
\text { Burnley } \\
\text { Rhondda } \\
\text { Rochdale }\end{array}$ & $\begin{array}{l}404 \\
328 \\
360 \\
288 \\
163\end{array}$ & $\begin{array}{l}\text { High mortality } \\
3336(27) \\
3304(30) \\
3318(28) \\
3273(32) \\
3237(42)\end{array}$ & $\begin{array}{r}7 \cdot 8 \\
8 \cdot 2 \\
10 \cdot 0 \\
8 \cdot 6 \\
6 \cdot 1\end{array}$ \\
\hline $\begin{array}{l}\text { High mortality } \\
\text { town group }\end{array}$ & 5 & $3294(14)^{\star}$ & $8 \cdot 1$ \\
\hline p (high-low differe & & $0 \cdot 12$ & 0.005 \\
\hline
\end{tabular}

^Based on between town differences

\begin{tabular}{|c|c|c|c|}
\hline & $\begin{array}{l}\text { Height (cm) } \\
\text { Mean (SEM) }\end{array}$ & $\begin{array}{l}\text { Body mass } \\
\text { index }\left(\mathrm{kg} / \mathrm{m}^{2}\right) \\
\text { Mean }(S E M)\end{array}$ & $\begin{array}{l}\text { Birthweight (g) } \\
\text { Mean (SEM) }\end{array}$ \\
\hline $\begin{array}{l}\text { Social class } \\
\text { I } \\
\text { II } \\
\text { IIIN } \\
\text { IIIM } \\
\text { IV } \\
\text { V }\end{array}$ & $\begin{array}{l}117.9(0 \cdot 3) \\
118 \cdot 2(0 \cdot 2) \\
117 \cdot 7(0 \cdot 3) \\
117 \cdot 3(0 \cdot 1) \\
116 \cdot 8(0 \cdot 2) \\
116.6(0 \cdot 4)\end{array}$ & $\begin{array}{l}15.66(0.10) \\
15.70(0.05) \\
15.80(0.09) \\
15.80(0.05) \\
15.72(0.08) \\
15.79(0.13)\end{array}$ & $\begin{array}{l}3292(35) \\
3368(18) \\
3381(30) \\
3312(16) \\
3313(27) \\
3242(46)\end{array}$ \\
\hline ANCOVA & $\mathrm{p}<0.0001$ & $p=0.61$ & $p=0.02$ \\
\hline
\end{tabular}

high mortality towns, although the mean differences do not achieve conventional levels of statistical significance (mean difference $34 \mathrm{~g}, 95 \% \mathrm{CI}$ -10 to $78, p=0 \cdot 12$ ). However, the proportion of children with low birthweight (less than $2.5 \mathrm{~kg}$ ) was higher in the high mortality towns $(8.1 \%)$ than in the low mortality towns $(5.5 \%)(p=0.005)$. Variation in leftward skew accounts for much of the variation in the prevalence of low birthweight between towns; overall birthweight variance did not differ importantly between towns. Town mean birthweights were positively correlated with town mean heights $(r=0.54)$ but showed litle relationship with body mass index $(r=-0 \cdot 24)$.

Both height and birthweight were strongly related to social class, with subjects from manual, particularly unskilled manual, occupations being of lower birthweight and shorter stature (table IV). However, there was little evidence of a relationship between social class and body mass index (table IV). Adjustment of the differences in height between high and low mortality towns for the effect of social class resulted in a slight reduction of the mean difference (from $0.9 \mathrm{~cm}$ to $0.7 \mathrm{~cm} ; 95 \%$ CI 0.2 to 1.2 ) which however remained statistically significant $(p=0.02)$. The small difference in mean birthweight was halved (from $34 \mathrm{~g}$ to $17 \mathrm{~g} ; 95 \% \mathrm{CI}-26$ to $60, \mathrm{p}=0.4$ ). However, the difference in the proportion of low birthweights was little affected by adjustment for social class, changing only from $2.6 \%$ to $2.5 \%$ $(95 \% \mathrm{CI} 1 \cdot 1$ to $3 \cdot 9, \mathrm{p}=0.003)$.

AMBIENT TEMPERATURE AND HEIGHT: INFLUENCE ON BLOOD PRESSURE

\section{Ambient temperature}

In this study population a marked inverse relationship between room temperature and blood pressure was observed. The estimates of blood pressure change for a $1^{\circ} \mathrm{C}$ rise in room temperature were $-0.43 \mathrm{~mm} \mathrm{Hg}$ for systolic pressure and $-0.39 \mathrm{~mm} \mathrm{Hg}$ for diastolic pressure. Outdoor temperature showed similar relationships, which were abolished once the effect of room temperature was taken into account. However, mean room temperatures were identical in high and low mortality towns $\left(95 \% \mathrm{CI}-1.97\right.$ to $\left.1.97^{\circ} \mathrm{C}\right)$ and adjustment for room temperature had no effect on mean blood pressure differences between high and low mortality towns.

\section{Height}

In this study population height was strongly related to blood pressure. Estimates of blood pressure change for a $1 \mathrm{~cm}$ increase in height were $0.64 \mathrm{~mm} \mathrm{Hg}$ (SEM $0.03 \mathrm{~mm} \mathrm{Hg}$ ) for systolic pressure and $0.29 \mathrm{~mm} \mathrm{Hg}$ (SEM $0.02 \mathrm{~mm} \mathrm{Hg}$ ) for diastolic pressure. These relationships were independent of age and sex. The effect on mean blood pressures in the high and low mortality town groups of taking height into account were examined in a regression model standardised for height, age, and sex. Mean differences in both systolic and diastolic blood pressure were larger than those observed when standardised for age and sex alone, but still failed to achieve conventional levels of statistical significance (mean systolic difference $1.2 \mathrm{~mm} \mathrm{Hg}, 95 \% \mathrm{CI}-1.2$ to $3.6 \mathrm{~mm} \mathrm{Hg}, \mathrm{p}=0.28$; mean diastolic difference $0.6,95 \% \mathrm{CI}-1.4$ to $2.6 \mathrm{~mm} \mathrm{Hg}, \mathrm{p}=0.5$ ). 
Discussion

We have compared the health of British children born in the 1980s living in towns with exceptionally high and exceptionally low rates of adult cardiovascular mortality. While this study includes no inner city areas, the high mortality towns included have rates of cardiovascular mortality and perinatal mortality comparable with those of many inner city districts. Children in towns with high adult cardiovascular mortality are shorter, and have slightly higher body mass indices, than those in low mortality towns. Mean birthweights are lower and the proportion of low birthweight infants is higher in high mortality towns. However, the differences are small and are partly accounted for by differences in social class. Blood pressure and pulse rate show little variation between high and low mortality towns. Overall mean heights and weights are greater than those which formed the basis for current standards, ${ }^{21} 22$ supporting the case for new reference data. ${ }^{23}$ Mean blood pressures are consistent with those reported by the Brompton study in five year olds ${ }^{24}$ and the second American Task Force, ${ }^{25}$ once the systematic difference in systolic blood pressure measurement between the Dinamap 1846SX and the mercury sphygmomanometer ${ }^{15}$ is taken into account. The blood pressure values in this study are slightly higher than those in our earlier study ${ }^{4}$; this discrepancy is explained by the use of the current Dinamap child cuff size, which is slightly smaller than that used in the earlier study.

\section{BLOOD PRESSURE AND PULSE RATE}

The results of this study provided no confirmation of the earlier finding ${ }^{4}$ that town mean childhood blood pressure levels were related to town adult cardiovascular mortality rate. The $95 \%$ confidence intervals for the difference between high and low mortality towns $(-1.6$ to $2.8 \mathrm{~mm} \mathrm{Hg}$ systolic, -1.6 to $2.4 \mathrm{~mm} \mathrm{Hg}$ diastolic) make the presence of differences of the magnitude hypothesised on the basis of the earlier study most unlikely. The implication of this finding is that the relationship between town adult mean blood pressure and town adult cardiovascular mortality desribed in earlier studies in the $40-59$ year age group $^{2} 3$ and in the 25-29 age group, ${ }^{3}$ if apparent in these towns, develops after 5-7 years. A likely time of development would then be the adolescent years, during which the rate of blood pressure change with age is particularly steep. ${ }^{25}$ While the findings do raise the possibility that there is statistically significant variation in blood pressure levels between towns independent of cardiovascular mortality, the importance of this variation has yet to be established. Results for pulse rate follow a broadly similar pattern. There is marked variation in pulse rates between towns, but no strong evidence that pulse rates differ between towns with high and low cardiovascular mortality.

\section{HEIGHT AND BODY MASS INDEX}

The observations that children in towns with low adult cardiovascular mortality rates are taller and slightly leaner than those in high mortality towns are broadly consistent with the results of analyses of the British Birth Survey, a cohort of children born in 1970 and examined at age 10 years, in which the characteristics of children in areas with the highest and lowest cardiovascular mortality rates were compared. ${ }^{7}$ In that study, after standardisation for social class, children in the lowest mortality areas were on average $0.9 \mathrm{~cm}$ taller than those in the highest mortality areas and had a lower mean body mass index (mean difference $0.07 \mathrm{~kg} / \mathrm{m}^{2}$ ). The reasons for the difference in height and body mass index between towns with different cardiovascular mortality patterns remain to be established. In the present study population, heights of children are strongly correlated with both maternal heights $(r=0.88)$ and with paternal heights $(r=0.77)$. Positive, though much weaker, correlations are also observed for body mass index both in mothers $(r=0 \cdot 19)$ and in fathers $(r=0 \cdot 20)$. Moreover, parental heights are lower in high mortality towns both in mothers (mean difference $2.3 \mathrm{~cm}, 95 \% \mathrm{CI} 1.5$ to 3.2 ) and in fathers (mean difference $2.1 \mathrm{~cm}, 95 \%$ CI 1.1 to 3.0). Differences in body mass index in parents also follow a similar pattern to those seen in children, with higher mean indices being observed in high mortality towns both in mothers (mean difference $0.60 \mathrm{~kg} / \mathrm{m}^{2}, 95 \%$ CI 0.32 to 0.88 ) and in fathers (mean difference $0.63 \mathrm{~kg} / \mathrm{m}^{2}$, $95 \%$ CI 0.41 to 0.85 ). However, the association between parental and child heights and body mass indices is likely to reflect both genetic and shared environmental factors, ${ }^{26}$ which cannot be separated in the context of the present study.

The interpretation of the differences observed in height and body mass index depend on whether they are likely to persist into adult life and whether they are tending to increase or diminish over time. Predicting whether these differences will persist into adult life is difficult, because the experience of different cohorts may vary. In the case of height, the experience of the National Child Development Study cohort of children born in 1958 has been that geographical differences in height at age seven years persist essentially unchanged into adult life (Strachan Dpersonal communication). No reports on the extent to which geographical differences in body mass index in childhood persist into adult life are available. However, at the individual level it has been observed that overweight at seven years is related to overweight in adult life although the association is weak. ${ }^{27} 28$ Thus on present evidence it is likely that the differences in height and body build will tend to persist into adult life, although the extent to which they will do so is uncertain.

The assessment of secular trends in the differences in height or body mass index is also difficult, because none of the earliest studies reported is consistent with the present study either in age group or in sample selection. However, two observations suggest that differences in childhood height between high and low mortality areas may be diminishing. First, the differences observed in children are markedly smaller than those in parents, a finding consistent with observations made in the 1970 British Birth Survey cohort at 10 years. ${ }^{29}$ Second, geographical variations in height in the present study are smaller than those observed in both the National Child Development Study of children born in 1958 and the British Birth Survey of children born in $1970 .^{29}$ 


\section{BIRTHWEIGHT}

The observations that both mean birthweight and the proportion of low birthweight may differ between high and low mortality towns are supported by data from other sources, although these tend to emphasise the small size of the differences. Mean birthweights in areas of widely differing cardiovascular mortality were presented in the analysis of the British Birth Cohort referred to earlier. ${ }^{7}$ Although mean birthweights were higher in areas of high cardiovascular mortality, the mean difference in birthweight between the highest and lowest mortality groups was extremely small (17 g) and did not approach conventional levels of statistical significance. The validity of the findings on differences in the proportion of low birthweight between high and low mortality towns has been examined using OPCS data based on all births in the health districts corresponding to the study towns over a six year period during the $1980 \mathrm{~s}^{30}$ These data, which are less influenced by the survival effects that are a potential source of bias in the study data, are consistent with the finding that the proportion of low birthweight may be higher in high mortality towns, but suggest that the difference in the proportion of low birthweight may be even smaller $(1.5 \%)$ than that described in the study $(2 \cdot 6 \%)$.

\section{IMPLICATIONS FOR FUTURE HEALTH AND MORTALITY}

What are the implications of these findings for the future health of this cohort of children born in the 1980s? Two particular questions need to be addressed. First, to what extent are the differences in height and body mass index observed likely to influence future health and mortality? Second, what are the implications of recent hypotheses emphasising the possibility of direct relationships between fetal and infant life and adult disease, particularly cardiovascular disease, for this cohort of children?

Both the differences in height and those in body mass index may be relevant to the future health of the children studied. Relationships between short adult stature and increased mortality in adult life have been described, both for all cause mortality and for ischaemic heart disease mortality. ${ }^{56}$ The extent to which height itself is responsible for the relationship, rather than other social factors related to height, is still debated. ${ }^{31}$ Moreover, it is possible that lung function, rather than height itself, is the factor directly responsible for the relationship. ${ }^{6}$ However, even if the relationship between height and mortality is a direct one, the consequences of the differences in height described in the present study are unlikely to be large. In the British Regional Heart Study a decrease in adult height of approximately $9 \mathrm{~cm}$ was associated with a twofold increase in mortality from ischaemic heart disease. ${ }^{6}$ The strength of the relationship was halved after standardisation for social class and other standard cardiovascular risk factors; a relationship of similar magnitude was observed in the Whitehall Study. ${ }^{5}$ Even if the differences in height observed between high and low mortality towns in the presnt study $(0.9 \mathrm{~cm}$ unadjusted, $0.6 \mathrm{~cm}$ adjusted for social class) increase twofold by adult life, the associated cardiovascular risk is likely to be relatively small. The differences in body mass index may also have implications for future mortality patterns, since higher body mass indices in adult life are associated with increased mortality both from cardiovascular and non-cardiovascular causes. ${ }^{32}$ However, as argued above, the implications of the present findings in children for future differences in adult body mass index between high and low mortality towns are difficult to predict.

Recent reports have emphasised the possibility of a direct link between fetal and infant experience and the development of later disease, particularly cardiovascular disease. ${ }^{7-10}$ The demonstration of ecological associations between infant mortality and ischaemic heart disease mortality, ${ }^{11}$ and between maternal mortality and stroke mortality, ${ }^{12}$ has led to the suggestion that early life influences might play an important part in explaining geographical variation in cardiovascular disease in Great Britain. ${ }^{7}$ More detailed ecological analyses have led to the suggestion that both the intrauterine and postnatal environments are related to the development of ischaemic heart disease, while the intrauterine environment alone is related to stroke. ${ }^{10}$ The geographical differences in childhood height suggest that there are persistent differences between the postnatal environments of high and low mortality towns, although, as has been argued above, the differences in height are likely to be diminishing and their consequences for future mortality are likely to be limited. In the hypotheses relating the intrauterine environment to later cardiovascular disease, birthweight has occupied a central role. Low birthweight has been related to increased risk of mortality from ischaemic heart disease ${ }^{9}$ and to higher blood pressure levels both in childhood ${ }^{733}$ and in adulthood. ${ }^{8}$ However, the results of the present study imply that geographical differences, both in mean birthweights and in the proportion of low birthweight, between areas of high and low adult cardiovascular mortality are now small, a conclusion which is consistent with the findings of earlier analysis of the British Birth Survey of 1970 births $^{7}$ and with routine statistics on the prevalence of low birthweight. ${ }^{30}$ Moreover, the absence of any appreciable differences in childhood blood pressure or pulse rate, two factors suggested to link intrauterine circumstances and adult cardiovascular risk, ${ }^{7}$ between high and low cardiovascular mortality towns again provides no support for the view that childhood blood pressure forms an important link between intrauterine factors and cardiovascular risk on a geographical basis in this cohort. These observations suggest that, whatever the importance of intrauterine influences on geographical variation in cardiovascular disease in Great Britain in the past, the case for their continuing importance has still to be proved.

This study was supported by a project grant from the Coronary Artery Disease Research Association (CORDA). PHW was supported by the Wellcome Trust and the British Heart Foundation, OP by the Chest, Heart and Stroke Association, and MW by the British Heart Foundation. We thank the members of the Research Team (Jenny Ashdown RGN, Wendy Cumper RGN, Sally Hirons RGN, Sharon Keegan Cumper RGN, Sally Hirons RGN, Sharon Keegan
RGN, Vivienne Howse) and the schools, parents and 
children involved in this study for their cooperation. We are grateful to Professor A G Shaper for his comments on the paper.

1 Rose G. Sick individuals and sick populations. Int $\mathcal{f}$ Epidemiol 1985; 14: 32-8.

Shaper AG, Pocock SJ, Walker M, Cohen NM, Wale CI, Thompson AG. British Regional Heart Study: cardiovascular risk factors in middle-aged men in 24 towns. $B M \mathcal{F}$ 1981; 283: 179-86.

3 Bruce NG, Cook DG, Shaper AG, Thompson AG Geographical variations in blood pressure in British me and women. $\mathcal{f}$ Clin Epidemiol 1990; 43: 385-98

4 Whincup PH, Cook DG, Shaper AG, Macfarlane D, Walke $M$. Blood pressure in British children: associations with adult blood pressure and cardiovascular mortality. Lancet 1988; ii: 890-3.

5 Marmot MG, Shipley MJ, Rose G. Inequalities in death specific explanations of a general pattern? Lancet 1984; specific

6 Walker M, Shaper AG, Phillips AN, Cook DG. Short stature, lung function and risk of a heart attack. Int Epidemiol 1989; 18: 602-6.

7 Barker DJP, Osmond C, Golding J, Kuh D, Wadsworth MEJ. Growth in utero, blood pressure in childhood and adult life, and mortality from cardiovascular disease. $B M \mathcal{Y}$ 1989; 298: 564-7.

8 Barker DJP, Bull AR, Osmond C, Simmonds SJ. Fetal and placental size and risk of hypertension in adult llife. $B M \mathcal{J}$ placental size and risk of hypertension in adult life. $B M Y$ 1990; 301: 259-62.

Barker DJP, Winter PD, Osmond C, Margetts B, Simmond SJ. Weight in infancy and death from ischaemic heart disease. Lancet 1989; in: 57

Barker DJP, Osmond C, Law CM. The intrauterine and early postnatal origins of cardiovascular disease and chronic bronchitis. F Epidemiol Community Health 1989; 43: 237-40.

11 Barker DJP, Osmond C. Infant mortality, childhood nutrition and ischaemic heart disease in England and Wales. Lancet 1986; i: 1077-81.

12 Barker DJP, Osmond C. Death rates from stroke in England and Wales predicted from past maternal mortality. $B M \mathcal{F}$ 1987; 295: 83-6.

13 Osmond C, Barker DJP. Ischaemic heart disease in England and Wales around the year 2000. 7 Epidemiol Community Health 1991; 45: 71-2.

14 Ramsey $M$. Non-invasive automatic determination of mean arterial pressure. Med Biol Eng Comput 1979; 17: 11-18.

15 Whincup PH, Bruce NG, Cook DG, Shaper AG. The Dinamap 1846SX automated blood pressure recorder: comparison with the Hawksley random zero sphygmomanometer under field conditions. If Epidemiol Community Health 1992; 46: 164-9.

16 Frohlich ED, Grim C, Labarthe DR, et al. Recommendations for human blood pressure determinations by mendations for human blood pressure determinations by appointed by the Steering Committee, American Heart Association. Circulation 1988; 77: 502-14.

17 Eaton-Evans J, Dugdale AE. Recall by mothers of the birth weights and feeding of their children. Hum Nutr Appl Nutr 1986; 40A: 171-5.

18 Office of Population Censuses and Surveys. Occupational mortality: childhood supplement. The Registrar General's Decennial Supplement for England and Wales 1979-80, 1982-3. Series DS, no 8. London: HMSO, 1988.

19 Wilcosky TC, Chambless LE. A comparison of direct adjustment and regression adjustment of epidemiologic measures. $f$ Chron Dis $1985 ; 38: 849-56$.

20 McKeigue PM, Marmot MG, Syndercombe Court YD, et al. Diabetes, hyperinsulinaemia, and coronary risk factors in Bangladeshis in East London. Br Heart $\mathcal{f} 1988 ; 60$ : $390-6$.

21 Tanner JM, Whitehouse RH, Takaishi M. Standards from birth to maturity for height, weight, height velocity and weight velocity in British children 1965. Arch Dis Child 1966; 41: 454-71.

22 Tanner JM, Whitehouse RH, Takaishi $M$. Standards from birth to maturity for height, weight, height velocity and weight velocity in British children 1965. Arch Dis Child 1966; 41: 613-35.

23 Chinn S, Price CE, Rona RJ. Need for new reference curves for height. Arch Dis Child 1989; 64: 1545-53.

24 de Swiet M, Fayers P, Shinebourne EA. Blood pressure in 4-5 year-old children: the effects of environment and other factors in its measurement. $₹$ Hypertens $1984 ; 2$ : 501-5.

25 Task Force on blood pressure control in children: report of the second Task Force on blood pressure control in the second Task Force on blood press

26 Rona RJ. Genetic and environmental factors in the control of growth in childhood. Br Med Bull 1981; 37: 265-72.

27 Stark O, Atkins E, Wolff OH, Douglas JWB. Longitudinal study of obesity in the National Survey of Health and study of obesity in the National Survey

28 Miller FJW, Billewicz WZ, Thompson AM. Growth from birth to adult life of 422 Newcastle upon Tyne children. $B$ f Prev Soc Med 1972; 26: 224-30.

29 Barker DJP, Osmond C, Golding J. Height and mortality in the counties of England and Wales. Ann Hum Biol 1990; 17 $1-6$

30 Office of Population, Censuses and Surveys. OPCS Monitor, Series DH3. Infant and perinatal mortality: DHAs.1984-1989.

31 Davey Smith G, Shipley MJ, Rose G. The magnitude and causes of socioeconomic differentials in mortality: furthe evidence from the Whitehall Study. $\mathcal{F}$ Epidemiol Community Health 1990; 41: 265-70.

32 Wannamathee G, Shaper AG. Body weight and mortality in middle-aged British men: impact of smoking. BMf 1989 299: 1497-502.

33 Whincup PH, Cook DG, Shaper AG. Early influences on blood pressure: a study of children aged 5-7 years. $B M$ 1989; 299: 587-91. 